Chronic Obstructive Pulmonary Diseases: Journal of the COPD Foundation

\author{
Original Research
}

\title{
Age-Dependent Associations Between 25-Hydroxy Vitamin D Levels and COPD Symptoms: Analysis of SPIROMICS
}

Robert M. Burkes, MD, MSCR ${ }^{1}$ David J. Couper, $\mathrm{PhD}^{2}$ Igor Z. Barjaktarevic, $\mathrm{MD}, \mathrm{PhD}^{3}$ Christopher B. Cooper, MD ${ }^{4}$ Wassim W. Labaki, MD ${ }^{5}$ Meilan K. Han, MD 5 Prescott G. Woodruff MD, MPH Stephen C. Lazarus, $\mathrm{MD}^{6}$ Trisha M. Parekh, DO ${ }^{7}$ Robert Paine, III, MD ${ }^{8}$ Alejandro P. Comellas, $\mathrm{MD}^{9}$ Russell P. Bowler, MD, PhD ${ }^{10}$ Laura R. Loehr, MD, PhD ${ }^{11}$ Nirupama Putcha, MD, MHS ${ }^{12}$ Robert A. Wise, MD ${ }^{12}$ Todd T. Brown, MD, $\mathrm{PhD}^{13}$ M. Bradley Drummond, MD, MHS ${ }^{1}$

\section{Abstract}

Introduction: Age and vitamin D levels may affect symptom burden in chronic obstructive pulmonary disease (COPD). We used the Subpopulations and Intermediate Outcome Measures in COPD Study (SPIROMICS) to determine independent associations between vitamin $\mathrm{D}$ levels and COPD symptoms in different age strata.

Methods: Serum 25-hydroxy (OH)-vitamin D levels were modeled continuously and categorically $(<20 \mathrm{ng} / \mathrm{ml}$ versus $\geq 20 \mathrm{ng} / \mathrm{ml}$ ). Stratifying by age group (middle-age: $40-64$ years old and older: $>65$ years old), multivariable modeling was performed to identify relationships between 25-OH-vitamin D levels and the COPD Assessment Test (CAT), the modified Medical Research Council score (mMRC), the St George's Respiratory Questionnaire (SGRQ) total and subdomain scores, the Veterans' Specific Activity Questionnaire, and the 6-minute walk test distance.

Results: In the middle-aged group, each $5 \mathrm{ng} / \mathrm{ml}$ higher 25-OH-vitamin $\mathrm{D}$ level was independently associated with more favorable CAT score (-0.35[-0.67 to -0.03], $P=0.03)$, total SGRQ (-0.91[-1.65 to -0.17]; $P=0.02)$, and the SGRQ subdomains (Symptoms:-1.07[-1.96 to -0.18], $P=0.02$; Impact: -0.77 [-1.53 to -0.003], $P=0.049$; Activity: $-1.07[-1.96$ to -0.18 ], $P=0.02$ ). These associations persisted after the addition of comorbidity score, reported vitamin $\mathrm{D}$ supplementation, outdoor time, or season of blood draw to models. No associations were observed between 25-OH-vitamin D levels and symptom scores in the older age group.

Discussion: When controlled for clinically relevant covariates, higher 25-OH-vitamin D levels are associated with more favorable respiratory-specific symptoms and quality-of-life assessments in middle-age but not older COPD individuals. Study of the role of vitamin D supplementation in the symptom burden of younger COPD patients is needed.

\footnotetext{
Abbreviations: chronic obstructive pulmonary disease, COPD; Subpopulations and Intermediate Outcome Measures in COPD Study, SPIROMICS; serum 25-hydroxy, 25-OH; COPD Assessment Test, CAT; St George's Respiratory Questionnaire, SGRQ; Chronic Respiratory Disease Questionnaire, CRQ; body mass index, BMI; forced expiratory volume in 1 second, FEV $\mathbf{1}$; forced vital capacity, FVC; body mass index, BMI; American Thoracic Society, ATS; 6-minute walk test, 6MWT; modified Medical Research Council dyspnea scale, mMRC; minimal clinically important difference, MCID; Veteran's Specific Activity Questionnaire, VSAQ

Funding Support: RMB is supported by National Institutes of Health (NIH)/National Heart, Lung, and Blood Institute (NHLBI) grant F32HL 143867. MBD is supported by NIH/NHLBI grant R01HL125432. SPIROMICS was supported by contracts from the NIH/NHLBI (HHSN268200900013C, HHSN268200900014C, HHSN268200900015C, HHSN268200900016C, HHSN268200900017C, HHSN268200900018C, HHSN268200900019C, HHSN268200900020C), and grants from the NIH/NHLBI (U01 HL137880. U01 HL137880 and U24 HL141762), and supplemented by contributions made through the Foundation for the NIH and the COPD Foundation from AstraZeneca/MedImmune, Bayer, Bellerophon Therapeutics, Boehringer-Ingelheim Pharmaceuticals, Inc., Chiesi Farmaceutici S.p.A. Forest Research Institute, Inc., GlaxoSmithKline, Grifols Therapeutics, Inc., Ikaria, Inc., Novartis Pharmaceuticals Corporation, Nycomed
} 
GmbH, ProterixBio, Regeneron Pharmaceuticals, Inc., Sanof, Sunovion, Takeda Pharmaceutical Company, Theravance Biopharma, and Mylan.

Date of Acceptance: March 31, 2021 | Published Online Date: April 6, 2021

Citation: Burkes RM, Couper DJ, Barjaktarevic IZ, et al. Age-dependent associations between 25-hydroxy vitamin D levels and COPD symptoms: analysis of SPIROMICS. Chronic Obstr Pulm Dis. 2021;8(2):277-291. doi: https://doi.org/10.15326/jcopdf.2020.0180

1 Division of Pulmonary Diseases and Critical Care Medicine, University of North Carolina-Chapel Hill, Chapel Hill, North Carolina, United States

2 Gillings School of Global Public Health, University of North Carolina-Chapel Hill, Chapel Hill, North Carolina, United States

3 Division of Pulmonary, Critical Care, and Sleep Medicine, David Geffen School of Medicine, University of California-Los Angeles, Los Angeles, California, United States

4 Departments of Medicine and Physiology, David Geffen School of Medicine, University of California-Los Angeles, Los Angeles, California, United States

5 Division of Pulmonary and Critical Care Medicine, University of Michigan, Ann Arbor, Michigan, United States

6 Division of Pulmonary, Critical Care, Allergy, and Sleep

Medicine, University of California-San Francisco, San Francisco, California, United States

7 Division of Pulmonary, Critical Care, Allergy, and Sleep Medicine, University of Alabama-Birmingham, Birmingham, Alabama, United States

8 Division of Pulmonary Medicine, University of Utah, Salt Lake City, Utah, United States

9 Division of Pulmonary, Critical Care, and Occupational Medicine, University of Iowa, Iowa City, Iowa, United States

10 Division of Pulmonary, Critical Care, and Sleep Medicine, National Jewish Hospital, Denver, Colorado, United States

11 Division of General Medicine and Clinical Epidemiology, University of North Carolina, Chapel Hill, North Carolina, United States

12 Division of Pulmonary and Critical Care, Johns Hopkins University, Baltimore, Maryland, United States

13Division of Endocrinology and Metabolism, Johns Hopkins University, Baltimore, Maryland, United States

\section{Keywords:}

COPD; COPD outcomes; COPD epidemiology; vitamin D; COPD symptoms

\section{Address correspondence to:}

Robert M. Burkes, MD

231 Albert Sabin Way, ML 0564

Cincinnati, $\mathrm{OH} 45267$

Phone: (724)730-3862

Email: burkesrt@ucmail.uc.edu

\section{This article contains an online supplement.}

\section{Introduction}

Chronic obstructive pulmonary disease (COPD) is defined as obstruction on spirometry, the presence of clinical risk factors, and symptoms consistent with
COPD diagnosis. ${ }^{1,2}$ Assessment of COPD symptoms is an essential part of the COPD treatment algorithm ${ }^{3}$ and a clinical endpoint for drug investigation. ${ }^{4-7}$ COPD symptoms lead to more missed days of work, unemployment, use of health care resources, and financial difficulties. ${ }^{8}$ Previous studies have shown middle-aged (aged 45-65) persons have worse symptom scores than older (>65 years-old) counterparts independent of common medical and psychological comorbidities. ${ }^{9}$ Middle-aged COPD patients may be affected by lower symptom tolerance, ${ }^{10}$ greater perception of and discomfort from increasing ventilatory loads, ${ }^{11}$ increased prevalence of depression, ${ }^{12}$ and/or poorer access to medical care due to lack of medical insurance. ${ }^{13}$ Comorbidities play an important role in the quality of life of patients with COPD and are associated with worse reported symptoms. ${ }^{14}$ Also, younger persons with alpha-1 proteinase inhibitor deficiency and concomitant COPD were described as having higher rates of depression and poorer quality-of-life scores. ${ }^{12}$ Younger patients with poorer health status and vitamin $\mathrm{D}$ deficiency have been described in other chronic conditions. ${ }^{15,16}$ To this end, we believe that younger persons with COPD are a population with differential disease expression and identifying risk factors for increased symptoms in this population is potentially beneficial to the approach of younger persons with COPD and/or those with "early" COPD. ${ }^{17}$

Vitamin D deficiency is present in $40 \%-70 \%$ of COPD patients ${ }^{18,19}$ and is of particular interest due to the potential effects of vitamin $D$ on muscle strength and physical performance, ${ }^{20}$ as well as exacerbations $^{21}$ and lung function decline. ${ }^{22}$ Higher 25-hydroxy (OH)-vitamin D levels have been associated with improved COPD qualityof-life metrics in a small study. ${ }^{20}$ However, there was no improvement in Chronic Respiratory Disease Questionnaire (CRQ) with vitamin D supplementation in a randomized controlled trial. ${ }^{6}$ Other studies describe poorer mobility and gait in vitamin $\mathrm{D}$ deficient persons, ${ }^{23}$ which may potentially be manifested in symptom scores in younger persons 
with COPD. Response to pulmonary rehabilitation is also thought to be blunted in those with low 25-OHvitamin $\mathrm{D}$ levels. ${ }^{24}$ The $25-\mathrm{OH}-$ Vitamin $\mathrm{D}$ levels may reflect overall poor health status associated with global functional decline in COPD. ${ }^{25}$ In COPD, lower 25-OH-vitamin $\mathrm{D}$ levels present a modifiable risk factor that may be associated with increased symptom burden, potentially more impactful in middle-aged persons with COPD. ${ }^{9}$ However, to date the association between age, 25-OH-vitamin D levels, and reported COPD symptoms has not been described in the literature.

We have previously shown that 25-OH-vitamin $D$ levels are associated with poor lung function and COPD exacerbation outcomes. ${ }^{22}$ The analysis presented here extends the exploration of vitamin $D$ in COPD through an evaluation of vitamin D levels and symptoms across age groups, previously unexplored in this well-defined, multicenter COPD cohort. By leveraging the detailed demographic, clinical, and symptoms data from the multicenter, prospective Subpopulations and Intermediate Outcome Measures in COPD Study (SPIROMICS), ${ }^{26}$ we characterize the independent associations between younger age, 25-OH-vitamin $\mathrm{D}$ deficiency, and pulmonary symptoms in persons with COPD. We hypothesize that lower 25-OH-vitamin D levels will be associated with a worse symptoms profile in a young COPD cohort, independent of other comorbidities.

\section{Methods}

\section{Study Participants}

SPIROMICS is a multicenter, observational, prospective, cohort study including participants who are current or former smokers ( $\geq 20$ pack years) and nonsmoking controls, with or without chronic airflow obstruction, between the ages of 40-80 ( $n=2974)$ at recruitment from 2011-2016. ${ }^{26}$ The analytical cohort includes SPIROMICS participants with spirometry confirmed COPD (post-bronchodilator forced expiratory volume in 1 second to forced vital capacity $\left[\mathrm{FEV}_{1} / \mathrm{FVC}\right]<0.70$ ), available clinical data, and serum vitamin $D$ measurements $(\mathrm{N}=1621)$ (Figure 1). Institutional review boards at each center approved SPIROMICS and all participants provided informed, written consent.

\section{Figure 1. Consort Diagram Showing Participant Selection Process}

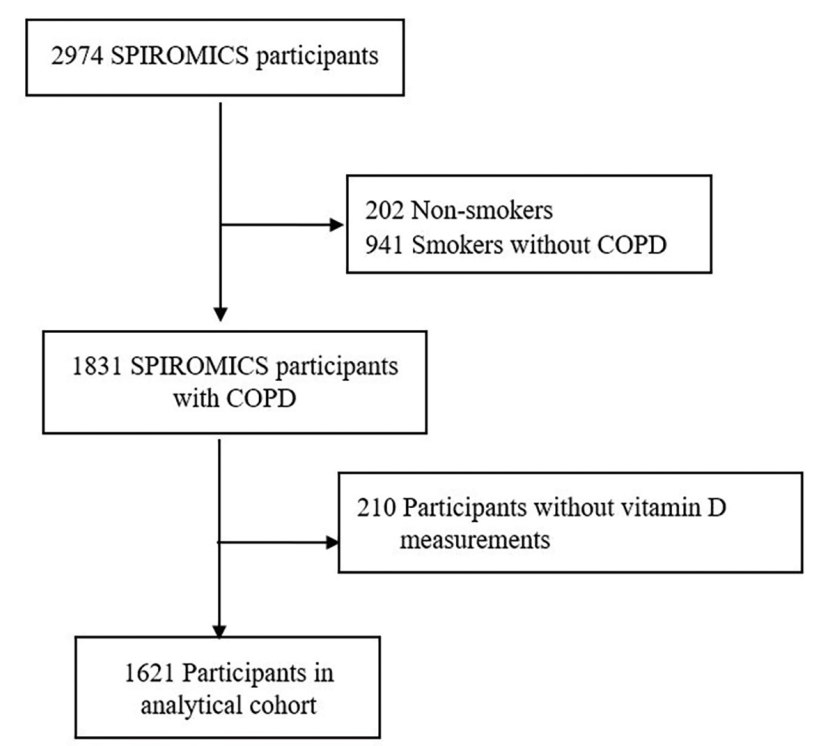

\section{Data Collection}

Demographic data, past medical history, smoking status (current versus former), smoking history (pack years), body mass index (BMI), and participantreported vitamin D supplementation or multivitamin usage were collected at enrollment (baseline). Participants who reported any type of supplementation that contained vitamin D (e.g., vitamin D, multivitamin with D) were abstracted as reporting vitamin $D$ supplementation. Individuals who reported other forms of supplements without mention of vitamin $D$ (e.g., vitamin use, multivitamin) were not recorded as taking vitamin $\mathrm{D}$ supplementation. The dose, frequency, and compliance with supplement was determined. Pre- and post-bronchodilator spirometry was performed in accordance with the American Thoracic Society (ATS)-European Respiratory Society guidelines ${ }^{27}$ for the measurement of FEV 1 and FVC. The 6-minute walk test (6MWT) conducted in accordance with ATS criteria was completed at the time of enrollment. Frequent exacerbation was defined as 2-or-more reported total exacerbations (any worsening of COPD symptoms requiring therapy and/or unscheduled health care encounters) in the year prior to enrollment. Serum 25-OHvitamin $\mathrm{D}$ levels were measured from stored samples of SPIROMICS participants with an $\mathrm{FEV}_{1} / \mathrm{FVC}<0.70$ which were collected at the baseline visit using radioimmunoassay (iDS, Enzyme Immunoassay; 
intra-assay coefficient of variance: $8.14 \%$, limit of blank: $1.8 \mathrm{ng} / \mathrm{ml}$ and limit of detection: $3.7 \mathrm{ng} / \mathrm{ml}$ ) as described previously. ${ }^{22}$

Participant-report outcomes collected at enrollment and incorporated in this analysis include: (1) modified Medical Research Council (mMRC) score (on a 0-4 scale with higher values representing worse breathlessness), ${ }^{28}$ (2) COPD Assessment Test ([CAT] on a 0-40 scale with higher scores representing worse COPD symptoms with suggested minimal clinically important difference [MCID] of 2), ${ }^{29}$ and (3) SGRQ (on a 0-100 scale over 3 subdomains [symptoms, activity, impact] with higher scores representing worse COPD symptoms with a 4-point decrement [range between 2-8] generally thought to be MCID). ${ }^{30,31}$ The Veteran's Specific Activity Questionnaire ([VSAQ] on a 1-13 scale with higher scores correlating to better patient-reported aerobic capacity) and 6MWT (measured in meters ambulated in 6 minutes) were used to approximate physical functioning of participants. ${ }^{32}$

\section{Statistical Methods}

Descriptive statistics were used to determine the proportion of middle-aged ( $<65$ years-old) versus older ( $\geq 65$ years-old) participants in the cohort as well as distribution of $25-\mathrm{OH}$-vitamin $\mathrm{D}$ within the cohort. For analyses, vitamin D levels (exposure) were modeled continuously (per $5 \mathrm{ng} / \mathrm{ml}$ ) and dichotomously as sufficient $(\geq 20 \mathrm{ng} / \mathrm{ml})$ versus deficient $(<20 \mathrm{ng} / \mathrm{ml})$. Two-sample $t$-test or MannWhitney $\mathrm{U}$ tests for continuous variables (depending on skew of data) or chi-squared tests (for categorical variables) were performed to compare demographic, clinical factors, and symptom scores associated with age group and 25-OH-vitamin D sufficiency. Similar bivariate methods were used to identify differences between middle-aged and older participants as performed by Martinez et al. ${ }^{9}$ Spearman's correlation was used to determine the relationship between symptoms and vitamin D levels modeled continuously. The mMRC, CAT, SGRQ total and subdomains scores, and VSAQ outcomes were analyzed as continuous scores in linear regression. The 6MWT distance was modeled continuously as meters walked. Covariates were based on a conceptual framework ${ }^{33}$ and included age, race, sex, current smoking, pack years smoked, $\mathrm{BMI}$, and $\mathrm{FEV}_{1}$.

Differential outcomes on patient-reported symptom tools in the SPIROMICS cohort between the older and middle-aged have been previously noted. ${ }^{9}$ Based on this finding, we performed multivariable linear analyses stratified by these 2 age groups. Covariates included sex, race, current smoking, pack years smoked, BMI, and FEV 1 . As previously described, a score for physical and psychological comorbidities, ${ }^{14}$ to assess vitamin $\mathrm{D}$ deficiency associations independent of comorbid disease, was added in a separate analysis to determine if $25-\mathrm{OH}$ vitamin $\mathrm{D}$ levels were associated with poor symptom scores independent of other comorbidities. The comorbidity score is a total count of COPD-related comorbidities (score range 0-10). Sensitivity analyses of statistically significant multivariable models were performed with addition of season of blood draw, use of vitamin D or multivitamin supplementation combined to create a vitamin D use variable, patient-reported per-day time spent outdoors in the year prior to enrollment, and geographic site of blood draw. We also performed the above analyses with the removal of those on vitamin $\mathrm{D}$ supplementation ( $\mathrm{n}=180$ removed), modeling lung function as $\mathrm{FEV}_{1} \%$ predicted (race and sex removed from models to avoid collinearity), and as an interaction term between vitamin D sufficiency and age. As the relationship between vitamin $\mathrm{D}$ metabolism and race is differential, ${ }^{34}$ we also subdivided the middle-aged cohort by race and presented the associations with 25-OH-vitamin $\mathrm{D}$ and respiratory symptoms. For all comparisons, $P<0.05$ was considered significant. Statistical analysis was performed using STATA 15.1 (STATA Corp, College Station, Texas).

\section{Results}

\section{Description of Cohort}

Of the 1621 participants, 995 (59\%) were aged 65 years or older (Table 1 ). The median age in the entire cohort was 66 years-old (Q1-Q3, 60-71 years-old). In the entire cohort, $42 \%$ were female and $14 \%$ reported Black race. There were $33 \%$ current smokers and a median of 46 pack years smoked (Q1-Q3, 35-62 pack years). A total of $14 \%$ of the cohort reported 2 or more COPD exacerbations in the year prior to enrollment and $24 \%$ of the cohort reported chronic bronchitis. The mean 25-OH-vitamin D level was 30.0 (standard deviation [SD] 12.4), median 28.9 (Q1-Q3, 21.336.5 ), and levels ranged from minimum of $6.59 \mathrm{ng} / \mathrm{ml}$ to maximum of $106 \mathrm{ng} / \mathrm{ml}$ (Figure 2). A total of 


\section{Table 1. Cohort Characteristics of SPIROMICS Participants Included in this Analysis Stratified by Age $^{\mathrm{a}}$}

\begin{tabular}{|c|c|c|c|c|}
\hline & Overall & $\begin{array}{l}\text { Middle Aged } \\
(<65 \text { years old })\end{array}$ & $\begin{array}{c}\text { Older } \\
\text { ( } \geq 65 \text { years old })\end{array}$ & $P$-value \\
\hline $\mathrm{N}$ & 1621 & 666 & 955 & \\
\hline Age, years & $66(60-71)$ & $58(54-62)$ & $70(67-74)$ & $<0.001$ \\
\hline Black race & $226(13.9)$ & $152(22.8)$ & $74(7.8)$ & $<0.001$ \\
\hline Female sex & $680(42.0)$ & $298(44.7)$ & $382(40.0)$ & 0.06 \\
\hline BMI, $\mathrm{kg} / \mathrm{m}^{2}$ & $27.5(5.3)$ & $27.6(6.0)$ & $27.5(5.1)$ & 0.73 \\
\hline Current Smoker & $532(33.4)$ & $327(50.2)$ & $205(21.8)$ & $<0.001$ \\
\hline Pack Years Smoked & $46(35-62)$ & $42(33-57)$ & $50(38-68)$ & $<0.001$ \\
\hline FEV $_{1}, \mathrm{~L}$ & $1.64(1.15-2.28)$ & $1.67(1.09-2.30)$ & $1.61(1.17-2.24)$ & 0.72 \\
\hline FEV1, \%predicted & $61(44-78)$ & $57(38-74)$ & $64(46-80)$ & $<0.001$ \\
\hline FVC, L & $3.27(2.55-4.09)$ & $3.30(2.59-4.13)$ & $3.23(2.51-4.05)$ & 0.10 \\
\hline FVC, \%predicted & 89 (75-102) & $86.3(72.2-99.0)$ & $90.4(77.2-104.4)$ & $<0.001$ \\
\hline 2+ Exacerbations in Prior Year & $225(14.1)$ & $127(19.3)$ & $98(10.4)$ & $<0.001$ \\
\hline Chronic Bronchitis & $378(24.0)$ & $205(31.4)$ & $173(18.9)$ & $<0.001$ \\
\hline Serum Vitamin $\mathbf{D}, \mathrm{ng} / \mathrm{ml}$ & 28.9 (21.3-36.5) & $25.6(18.4-33.6)$ & $30.8(23.6-38.2)$ & $<0.001$ \\
\hline Vitamin D Supplementation & $180(11.1)$ & 57 (8.56) & $123(12.9)$ & 0.01 \\
\hline Outdoor Time, hrs/day & $3(2-5)$ & $4(1-6)$ & $3(2-5)$ & 0.001 \\
\hline \multicolumn{5}{|l|}{ Baseline Comorbidities } \\
\hline Congestive Heart Failure & $47(2.93)$ & $11(1.67)$ & $36(3.81)$ & 0.01 \\
\hline Coronary Artery Disease & $174(10.9)$ & $42(6.39)$ & $132(14.0)$ & $<0.001$ \\
\hline Diabetes & $227(14.2)$ & $83(12.6)$ & $144(15.2)$ & 0.14 \\
\hline History of Stroke & $70(4.36)$ & $28(4.26)$ & $42(4.44)$ & 0.86 \\
\hline Sleep Apnea & $304(19.9)$ & $125(20.1)$ & $179(19.7)$ & 0.83 \\
\hline Total Comorbidities & $2(1-4)$ & $2(1-4)$ & $2(1-3)$ & 0.40 \\
\hline $\begin{array}{l}\text { Average Time Spent Outdoors in } \\
\text { Year Prior, hours per day }\end{array}$ & $3.0(2.0-5.3)$ & $3.5(2.0-5.6)$ & $3.0(2.0-5.0)$ & 0.001 \\
\hline \multicolumn{5}{|l|}{ 6-minute Walk Test } \\
\hline Total distance & $392(127)$ & $400(137)$ & $387(120)$ & 0.04 \\
\hline$\%$ predicted & $79.8(28.6)$ & $77.2(29.6)$ & 81.6 (27.6) & 0.003 \\
\hline Hypoxemia & 39 (2.52) & $19(3.00)$ & $20(2.19)$ & 0.32 \\
\hline \multicolumn{5}{|l|}{$\begin{array}{l}\text { CAT } \\
\end{array}$} \\
\hline Total Score & $15(9-21)$ & $18(12-24)$ & $13(8-19)$ & $<0.001$ \\
\hline$\geq 10$ & $1121(72.9)$ & $532(83.3)$ & $595(65.5)$ & $<0.001$ \\
\hline \multicolumn{5}{|l|}{ mMRC } \\
\hline Total & $1(1-2)$ & $1(1-2)$ & $1(0-2)$ & $<0.001$ \\
\hline$\geq 2$ & $513(31.9)$ & $271(41.1)$ & 242 (25.6) & $<0.001$ \\
\hline \multicolumn{5}{|l|}{ SGRQ } \\
\hline Total & $37.3(22.1-51.6)$ & $44.1(30.4-59.7)$ & 31.4 (18.5-44.6) & $<0.001$ \\
\hline Symptoms & 52.5 (34.5-69.7) & $62.0(45.7-78.5)$ & $46.5(28.4-62.9)$ & $<0.001$ \\
\hline Impact & $21.7(9.71-37.1)$ & $30.3(15.4-46.6)$ & $16.2(7.47-30.2)$ & $<0.001$ \\
\hline Activity & $52.3(32.9-67.7)$ & 59.5 (39.6-79.7) & $46.0(26.6-65.2)$ & $<0.001$ \\
\hline VSAQ & $4(3-7)$ & $4(2-6)$ & $5(3-7)$ & $<0.001$ \\
\hline
\end{tabular}

aPresented as frequency with percentage for count variables or mean (standard deviation) or median (Q1-Q3) for continuous variables depending on skew.

$\mathrm{BMI}=$ body mass index; $\mathrm{FEV}_{1}=$ forced expiratory volume in 1 second; $\mathrm{FVC}=$ forced vital capacity; $\mathrm{CAT}=\mathrm{COPD}$ Assessment Test; $\mathrm{mMRC}=$ modified Medical Research Council dyspnea scale; SGRQ=St George's Respiratory Questionnaire; VSA =Veteran's Specific Activity Questionnaire 
$11 \%$ of participants reported either taking vitamin supplementation or a multivitamin. The median comorbidity score in the entire cohort was 2 (Q1-Q3, 1-4). The average reported outdoor time in the year prior to enrollment was 3 hours/day (Q1-Q3, 2-5.3 hours/day). In the total cohort, median $\mathrm{mMRC}$ score was 1 (Q1-Q3, 1-2), the median CAT score was 15 (Q1-Q3, 9-21), and median SGRQ total score was 37.3 (Q1-Q3, 22.1-51.6). The mean 6MWT distance was 392 meters (SD 127 meters) with a median VSAQ score of 4 (Q1-Q3, 3-7).

Older participants were less likely to be Black ( $8 \%$ versus $23 \%, P<0.001$ ), less likely to be current smokers (22\% versus $50 \%, P<0.001)$, but reported higher pack years smoked (50 pack years versus 42 pack years, $P<0.001)$. Older participants were less likely to report symptoms of chronic bronchitis (19\% versus $31 \%, P<0.001)$ and to have had 2 -or-more exacerbations in the year prior to enrollment $(10 \%$ versus $19 \%, P<0.001)$. The $25-\mathrm{OH}-$ Vitamin $\mathrm{D}$ levels were significantly higher in the older participants (30.8ng/ml versus $25.6 \mathrm{ng} / \mathrm{ml}, P<0.001)$. The older group was more likely to report some form of vitamin D supplementation or multivitamin use (13\% versus 9\%, $P=0.01)$. Comparing middle-aged to older participants, there was no difference in season of sample draw $(P=0.32)$ or total comorbidity score (2 versus $2, P=0.40)$. The older age group spent fewer hours-per-day outdoors than the middle-aged group (3 hrs/day versus $3.5 \mathrm{hrs} /$ day, $P=0.001$ ). The older

\section{Figure 2. Histogram Showing the Distribution of 25-OH-Vitamin D Levels in the Total Cohort}

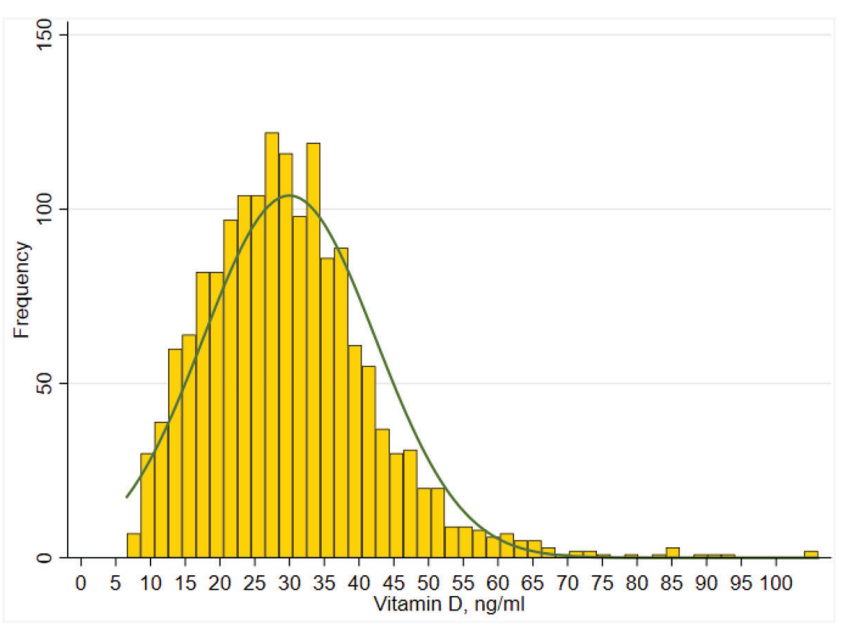

age group had a lower (better) median CAT score (13 versus $18, P<0.001)$, similar median $\mathrm{mMRC}$ but more favorable score distribution (median 1; [Q1-Q3, 0-2] versus [Q1-Q3, 1-2], $P<0.0010$ ), and a lower (better) total SGRQ score (31.4 versus 44.1, $P<0.001$ ). The older age group had a higher (better) VSAQ score (5 versus $4, P<0.001)$ while the middle-aged group had a longer average 6MWT distance (400 m versus 387 $\mathrm{m}, P=0.04)$.

\section{Continuous Vitamin D Serum Levels and Symptoms}

Across the entire cohort, Spearman's correlation showed a statistically significant correlation between better symptom scores and higher 25-OH-vitamin D levels: CAT score $(r=-0.138), \operatorname{mMRC}(r=-0.103)$, total SGRQ ( $r=-0.179$ ), SGRQ subdomains (Symptoms $\mathrm{r}=-0.134$; Impact $\mathrm{r}=-0.174$; Activity $\mathrm{r}=-0.158)$, and VSAQ ( $r=0.120)(P<0.001$ for all comparisons).

In the total cohort, using multivariable linear regression adjusting for age, race, sex, smoking status, smoking history, $\mathrm{FEV}_{1}$, and BMI, a $5 \mathrm{ng} / \mathrm{ml}$ higher 25-OH-vitamin D level was associated with a 0.41 lower (better) total SGRQ score (95\% CI -0.79 to -0.04; $P=0.03$ ) (Table 2). A $5 \mathrm{ng} / \mathrm{ml}$ higher $25-\mathrm{OH}$ vitamin $D$ level was also associated with significantly more favorable scores for the SGRQ Impact (-0.40 [95\% CI -0.77 to -0.02 ], $P=0.04)$ and Activity (-0.52 [95\% CI -0.99 to -0.05$], P=0.03)$ subdomains. Further, in the total cohort, every $5 \mathrm{ng} / \mathrm{ml}$ higher level of 25-OH-vitamin $\mathrm{D}$ was associated with a statistically better VSAQ (0.06 [95\% CI 0.002 to 0.11 ]; $P=0.04$ ); however, there is no MCID reported for VSAQ in COPD patients. A single unit VSAQ increase represents an approximate $3.5 \mathrm{ml} / \mathrm{kg} / \mathrm{min}$ increase in oxygen consumption, and due to the magnitude of this point estimate, while statistically significant, is likely clinically negligible. ${ }^{35}$ Higher 25-OH-vitamin $D$ levels were not associated with changes in CAT score, mMRC, SGRQ Symptoms subdomain score, or $6 \mathrm{MWT}$ distance. Modeling using linear spline knots at clinical thresholds (e.g., $10 \mathrm{ng} / \mathrm{ml}, 20 \mathrm{ng} / \mathrm{ml}$, and $30 \mathrm{ng} / \mathrm{ml}$ of $25-\mathrm{OH}$-vitamin) did not identify any inflection points representing statistical differences above and below that threshold.

When stratifying the cohort into middle-aged and older participants, after adjustment for race, sex, current smoking, pack years smoked, BMI, and FEV 1 , in the middle-aged group, every $5 \mathrm{ng} / \mathrm{ml}$ higher $25-\mathrm{OH}$ - 
vitamin D level was associated with a significantly lower total SGRQ (-0.91 [95\% CI -1.65 to -0.17 ]; $P=0.02)$, and SGRQ subdomains of Symptoms $(-1.07$ [95\% CI -1.96 to -0.18$]$; $P=0.02)$, Impact $(-0.77$ [95\% CI -1.53 to -0.003$]$; $P=0.049)$, and Activity ( -1.07 [95\% CI -1.96 to -0.19 ]; $P=0.02$ ) (Table 2). There was also an association with better CAT score (-0.35 [95\% CI -0.67 to -0.03]; $P=0.03$ ). The mMRC, VSAQ, and $6 \mathrm{MWT}$ distance were not significantly associated with vitamin $\mathrm{D}$ levels in the middle-age group. The only significant association observed in the older age group was the SGRQ Impact score (-0.42 [95\% CT -0.83 to -0.0001$]$; $P=0.049)$. Predicted scores for CAT and SGRQ stratified by age based on 25-OHvitamin D level are shown in Figure 3 and Figure 4, respectively.

\section{Impact of Comorbidity Score on Vitamin D Level-Symptoms Associations}

Several factors that could impact vitamin D levels and symptom relationships were considered. Older participants had more frequent coronary artery disease (14\% versus 6\%; $P<0.001$ ) and congestive heart failure ( $4 \%$ versus $2 \% ; P=0.01$ ), but not other comorbidities or total comorbidity count (Table 1). Comorbidity score was added to the continuous 25-OH-vitamin D multivariable models described previously. In the overall cohort, significant associations were not attenuated (Supplementary Table 1 in the online supplement) when comorbidity score was added to the models. When stratifying by age, CAT (-0.39 [95\% CI -0.70 to -0.07 ]; $P=0.02)$ and SGRQ total ( -0.99 [95\% CI -1.70 to -0.29 ]; $P=0.02)$ remained statistically significant in the middle-aged cohort after adjustment for comorbidity. Inclusion of comorbidity score did not attenuate the relationships between SGRQ subdomains and continuous 25-OHvitamin $\mathrm{D}$ in middle-aged participants.

\section{Sensitivity Analysis}

Season of blood draw, participant-reported use of vitamin $\mathrm{D}$ or a multivitamin, and total participantreported outdoor time were added to the above statistically significant age-stratified multivariable

\section{Table 2. Multivariable Associations Displaying Mean Difference in Scores per $5 \mathrm{ng} / \mathrm{ml}$ Increase in Vitamin D in Overall Cohort ${ }^{\mathrm{a}}$ and Stratified by Age ${ }^{\mathrm{b}}$}

\begin{tabular}{|c|c|c|c|c|c|c|}
\hline & \multicolumn{2}{|l|}{ Overall } & \multicolumn{2}{|c|}{ Middle Aged } & \multicolumn{2}{|l|}{ Older } \\
\hline & $\begin{array}{c}\text { Mean Difference } \\
(95 \% \mathrm{Cl})\end{array}$ & $P$-value & $\begin{array}{c}\text { Mean Difference } \\
(95 \% \mathrm{Cl})\end{array}$ & $P$-value & $\begin{array}{c}\text { Mean Difference } \\
(95 \% \mathrm{Cl})\end{array}$ & $P$-value \\
\hline CAT & $\begin{array}{r}-0.09 \\
(-0.26 \text { to } 0.08)\end{array}$ & 0.28 & $\begin{array}{r}-0.35 \\
(-0.67 \text { to }-0.03)\end{array}$ & 0.03 & $\begin{array}{r}-0.05 \\
(-0.24 \text { to } 0.15)\end{array}$ & 0.65 \\
\hline mMRC & $\begin{array}{r}-0.01 \\
(-0.03 \text { to } 0.01)\end{array}$ & 0.32 & $\begin{array}{r}-0.01 \\
(-0.05 \text { to } 0.03)\end{array}$ & 0.63 & $\begin{array}{r}-0.014 \\
(-0.037 \text { to } 0.01)\end{array}$ & 0.22 \\
\hline SGRQ Total & $\begin{array}{r}-0.41 \\
(-0.79 \text { to }-0.04)\end{array}$ & 0.029 & $\begin{array}{r}-0.91 \\
(-1.65 \text { to }-0.17)\end{array}$ & 0.02 & $\begin{array}{r}-0.39 \\
(-0.82 \text { to } 0.04)\end{array}$ & 0.08 \\
\hline SGRQ Symptom & $\begin{array}{r}-0.31 \\
(-0.82 \text { to } 0.20)\end{array}$ & 0.23 & $\begin{array}{r}-1.07 \\
(-1.96 \text { to }-0.18)\end{array}$ & 0.02 & $\begin{array}{r}-0.12 \\
(-0.74 \text { to } 0.51)\end{array}$ & 0.72 \\
\hline SGRQ Impact & $\begin{array}{r}-0.40 \\
(-0.77 \text { to }-0.02)\end{array}$ & 0.04 & $\begin{array}{r}-0.77 \\
(-1.53 \text { to }-0.003)\end{array}$ & 0.049 & $\begin{array}{r}-0.42 \\
(-0.83 \text { to }-0.0001)\end{array}$ & 0.05 \\
\hline SGRQ Activity & $\begin{array}{r}-0.52 \\
(-0.99 \text { to }-0.05)\end{array}$ & 0.03 & $\begin{array}{r}-1.07 \\
(-1.96 \text { to }-0.19)\end{array}$ & 0.02 & $\begin{array}{r}-0.47 \\
(-1.02 \text { to } 0.08)\end{array}$ & 0.09 \\
\hline 6MWT, m & $\begin{array}{r}1.08 \\
(-1.44 \text { to } 3.61)\end{array}$ & 0.40 & $\begin{array}{r}1.15 \\
(-3.94 \text { to } 6.24)\end{array}$ & 0.66 & $\begin{array}{r}1.04 \\
(-1.76 \text { to } 3.85)\end{array}$ & 0.47 \\
\hline VSAQ & $\begin{array}{r}0.06 \\
(0.002 \text { to } 0.11)\end{array}$ & 0.044 & $\begin{array}{r}0.07 \\
(-0.03 \text { to } 0.17)\end{array}$ & 0.14 & $\begin{array}{r}0.05 \\
(-0.008 \text { to } 0.12)\end{array}$ & 0.09 \\
\hline
\end{tabular}

aAdjusted for age, race, sex, current smoking, pack years smoked, FEV 1 , and BMI

${ }^{\mathrm{b}}$ Adjusted for race, sex, current smoking, pack years smoked, $\mathrm{FEV}_{1}$, and BMI

CAT=COPD Assessment Test; $m M R C=$ modified Medical Research Council dyspnea scale; SGRQ=St George's Respiratory Questionnaire; $6 \mathrm{MWT}=6$-minute walk test; $\mathrm{VSAQ}=$ Veteran's Specific Activity Questionnaire 
Figure 3. Predicted Values from COPD Assessment Test Score Among Middleaged ( $<65$ years) ${ }^{\mathrm{a}}$ and Older-aged $\left(\geq 65\right.$ years $^{\mathrm{b}}$ Participants $^{\mathrm{c}}$

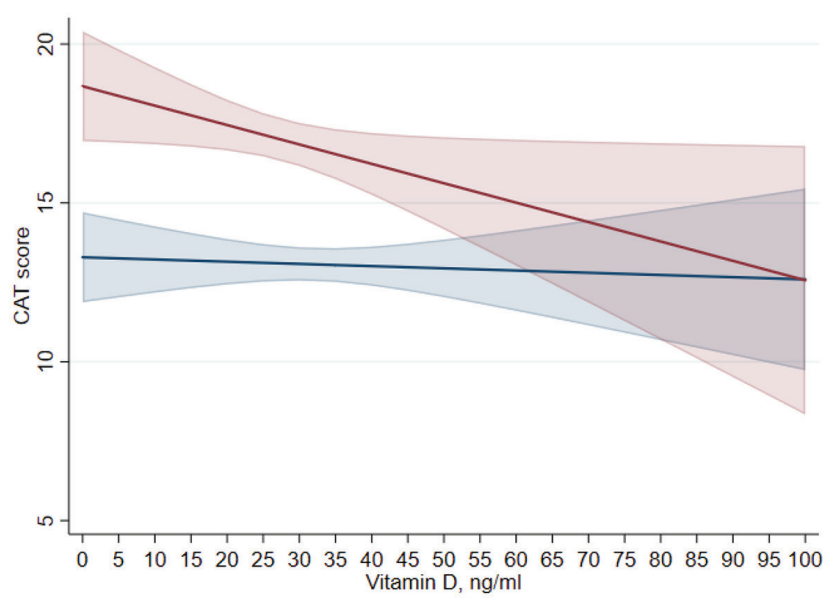

ared

bblue

cAcross vitamin D levels when controlled for race, sex, current smoking, smoking history, BMI, and baseline $\mathrm{FEV}_{1}$.

$\mathrm{BMI}=$ body mass index; $\mathrm{FEV}_{1}=$ forced expiratory volume in 1 second

\section{Figure 4. Predicted Values from Total} St George's Respiratory Questionnaire Score Among Middle-aged (<65 years) ${ }^{a}$ and Older-aged $(\geq 65 \text { years })^{\text {b }}$ Participants ${ }^{c}$

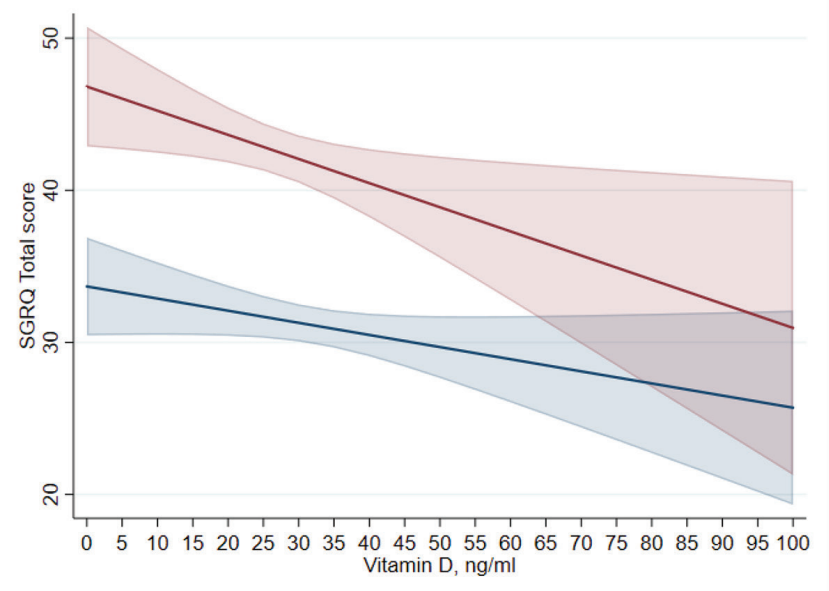

ared

bblue

cAcross vitamin D levels when controlled for race, sex, current smoking, smoking history, BMI, and baseline $\mathrm{FEV}_{1}$.

$\mathrm{BMI}=$ body mass index; $\mathrm{FEV}_{1}=$ forced expiratory volume in 1 second models (Supplementary Table 2 in the online supplement). Only the SGRQ Impact score relationship was attenuated in the middle-age group $(-0.72$ [95\% CI -1.54 to 0.03], $P=0.06)$ when the season of blood draw was added. The addition of study site (as an adjustment for latitude) did not attenuate independent associations between 25-OH-vitamin $D$ levels and symptom scores in the middle-aged cohort. Further, when 25-OH-vitmain D levels in the entire cohort were stratified into $<10 \mathrm{ng} / \mathrm{ml}, 10-20 \mathrm{ng} /$ $\mathrm{ml}$, $20-30 \mathrm{ng} / \mathrm{ml}$, and $>30 \mathrm{ng} / \mathrm{ml}$, the median SGRQ Total values were 56 versus 42 versus 37 versus 33 (analysis of variance $P=0.03$ ). Due to the relatively low number of participants with 25-OH-vitamin D levels $<10 \mathrm{ng} / \mathrm{ml}$ we were unable to evaluate for statistical relationships in multivariable analysis.

\section{Alternative Modeling of Age, Vitamin D, and Symptoms}

We examined the relationship between age, vitamin $D$ levels, and symptoms by alternative approaches. The relationship between 25-OH-vitamin $\mathrm{D}$ and symptoms in the middle-aged cohort was attenuated when an interaction term for middle-age and 25-OHvitamin D levels was added. For the interaction term among those who were classified as middle-aged and with 25-OH-vitamin D levels <20ng/ml: CAT (-0.17 [95\% CI -0.47 to 0.14]; $P=0.29$ ) and SGRQ Total (-0.39 [95\% CI (-1.10 to 0.32); $P=0.29])$. Modeling lung function by \%predicted $\mathrm{FEV}_{1}$ did not attenuate relationships between $5 \mathrm{ng} / \mathrm{ml}$ increases in $25-\mathrm{OH}$ vitamin D and CAT or SGRQ total in the whole cohort. Further, when those receiving some form of vitamin D supplementation were removed from the cohort the relationship with CAT score was not attenuated and there was a notable increase in the change per $5 \mathrm{ng} / \mathrm{ml}$ 25-OH-vitamin D increase and SGRQ Total score $(-1.05$ [95\% CI -1.43 to -0.67$]$; $P<0.001)$. In the agestratified cohort, when excluding those who reported some form of vitamin D supplementation, CAT $(-0.30$ [95\% CI -0.59 to -0.03$] ; P=0.034)$ and SGRQ Total ( -0.92 [95\% CI -1.58 to -0.26$] ; P=0.006)$ had a continued statistically significant improvement with every $5 \mathrm{ng} / \mathrm{ml}$ increase in $25-\mathrm{OH}$-vitamin D.

\section{The Relationship Between 25-Hydroxy Vitamin D, Middle Age, and Race}

Given the increased prevalence of Black race in the middle-aged cohort, we have subdivided the 
middle-aged cohort by race and have assessed the independent associations between a $5 \mathrm{ng} / \mathrm{ml}$ increase in 25-OH-vitamin $\mathrm{D}$ and respiratory symptoms when controlled for sex, current smoking, pack years smoked, and absolute $\mathrm{FEV}_{1}$. In White (-0.40 [95\% CI -0.69 to -0.12$] ; P=0.006)$ but not Black $(-0.10$ [95\% CI -0.78 to 0.57$]$; $P=0.77$ ) participants there was an association with a $5 \mathrm{ng} / \mathrm{ml}$ increase in 25-OH-vitamin $D$ and CAT score. For SGRQ Total, White (-1.10 [95\% CI -1.80 to -0.40$] ; P=0.002)$ but not Black (-0.54 [95\% CI -1.96 to 0.88 ]; $P=0.45$ ) participants had a significant association between increases in 25-OHvitamin D by $5 \mathrm{ng} / \mathrm{ml}$ and more favorable scores.

\section{Vitamin D Sufficiency and Symptoms}

In this cohort of 1621 participants, 1282 (79\%) were vitamin $D$ sufficient (vitamin $D \geq 20 \mathrm{ng} / \mathrm{ml}$ ) (Supplementary Table 3 in the online supplement). Vitamin D sufficient participants were more likely to be older (67 years versus 62 years; $P<0.001$ ), less likely to be Black ( $10 \%$ versus $29 \%$; $P<0.001$ ), less likely to be current smokers (29\% versus $48 \%$; $P<0.001)$, and more likely to report vitamin $D$ supplementation $(12 \%$ versus $6 \% ; P=0.001)$. Vitamin $\mathrm{D}$ sufficient participants had higher FEV 1 and FVC. Vitamin D sufficient participants had more favorable CAT scores (14 versus 17; $P<0.001$ ), SGRQ totals (34.8 versus 42.9; $P<0.001)$, and VSAQ scores (5 versus 4; $P<0.001)$.

In the overall cohort, after controlling for age, race, sex, BMI, FEV 1 , current smoking, and pack years in multivariable modelling, 25-OH-vitamin $\mathrm{D}$ level $>20 \mathrm{ng} / \mathrm{ml}$ was not associated with more favorable CAT scores, mMRC, total SGRQ and subdomains, VSAQ score, or 6MWT distance (Supplementary Table 4 in the online supplement). Further, there were no multivariable associations between vitamin D sufficiency and symptom outcomes observed when stratified by age.

\section{Discussion}

In this analysis of 1621 SPIROMICS participants, higher vitamin D levels when modeled continuously were associated with better CAT scores, SGRQ total, and SGRQ subdomain scores in middle-aged but not older age groups. These associations persisted after accounting for comorbidity burden. In the middle-aged group, an approximate $20 \mathrm{ng} / \mathrm{ml}$ higher vitamin D level was associated with a minimal clinically meaningful difference in total SGRQ (4 units). Further, associations were not attenuated by the addition of vitamin $D$ supplementation, outdoor time, and season of blood draw. In addition, when the middle-aged subgroup was further divided by race, the association between symptoms and vitamin $\mathrm{D}$ levels was restricted to non-Black participants, informing the need to explore the role of vitamin D in pulmonary health across demographic groups. These findings suggest that lower vitamin D levels may have a meaningful association with worse symptom scores in middle-aged COPD patients. However, based on current Global initiative for chronic Obstructive Lung Disease (GOLD) guidelines, ${ }^{36}$ vitamin $\mathrm{D}$ supplementation can be considered in deficient persons of all age groups to prevent poor COPD outcomes.

Associations between vitamin D levels and subjective symptoms may reflect overall poor health and/or effect of vitamin D on the musculoskeletal system. ${ }^{37}$ COPD patients with sufficient vitamin D levels show better muscle strength, ${ }^{20,38}$ and may accrue greater benefit from pulmonary rehabilitation. Vitamin D deficiency at enrollment in pulmonary rehabilitation is associated with poor health status and increased dropout. ${ }^{24}$ The median age of participants in these studies tended to be in the late-60s. Other studies have not described an increase in physical performance with improvement of nutritional status in muscle-wasted COPD patients. ${ }^{39}$ Also, vitamin D supplementation has not been shown to improve CRQ scores in 1 study. ${ }^{6}$ Participants in these studies also had a median age in the 60s. Our study adds to the body of literature by describing associations in a well-defined cohort and illustrating the potential importance of relatively young-aged COPD individuals in the vitamin $\mathrm{D}$-symptoms relationship. The mechanism driving the relationship between vitamin $\mathrm{D}$ levels and worse symptoms remains to be determined. Further studies evaluating the role of persons with very deficient vitamin $D$ levels $(<10 \mathrm{ng} / \mathrm{ml}$ ) and studies enriched to specifically determine associations in racially diverse groups, may be warranted to further understand this relationship.

Differential COPD symptom burden between age groups was observed in a prior SPIROMICS analysis. ${ }^{9}$ The relationships were independent of 
physical function and comorbidities. A separate cohort study further suggests that those developing COPD at a younger age have worse psychological and reported well-being outcomes. ${ }^{12}$ The response of symptoms and physical performance to vitamin D supplementation in middle-aged COPD participants is not well-studied. However, studies of vitamin D supplementation in younger participants with other chronic diseases have been performed. A cohort of participants (mean age 64) with osteoarthritis and an average increase in 25-OH-vitamin $\mathrm{D}$ from $20 \mathrm{ng} / \mathrm{ml}$ to $32 \mathrm{ng} / \mathrm{ml}$ with supplementation showed an improvement in health-related quality of life and grip strength. ${ }^{16}$ Further, supplementation in younger versus older volunteers with Parkinson's Disease (raising serum levels by an average $30 \mathrm{ng} / \mathrm{ml}$ ) has been associated with significantly better balance scores. ${ }^{15}$ COPD studies with older participants have not shown supplementation to be beneficial to symptom scores. ${ }^{6}$ These findings, combined with observations, suggest that low vitamin D levels may be of particular concern in younger persons with COPD. The role of the aging process, including cognitive decline 40 and lack of response to bronchodilators with age, ${ }^{41}$ may make the factors driving increased symptom perception in older persons different from younger persons. Also, there may be a "survivor" effect in the cohort, where the older group has more stable disease that has allowed for a longer life. The associations between the middle-age group, vitamin $\mathrm{D}$ levels, and COPD symptoms may describe a phenotype of younger, more symptomatic COPD patients who potentially represent a target for further intervention trials of the impact of vitamin $\mathrm{D}$ supplementation on COPD symptoms.

Independent associations between vitamin D levels and symptom scores persist when controlled for a validated comorbidity score. ${ }^{14}$ Comorbid conditions increase morbidity and mortality in COPD. ${ }^{14,42-46}$ We observe that the association between serum vitamin $D$ and symptom scores is independent of comorbidity burden. This finding suggests low serum vitamin $\mathrm{D}$ levels may represent a distinctly important comorbidity along with the other known long-term health issues that interface with the COPD disease state. Vitamin D metabolites may have a potential relationship with certain immune processes ${ }^{4-49}$ and 25-OH-vitamin $\mathrm{D}$ deficiency is associated with decreased musculoskeletal performance, ${ }^{23,25,37,50}$ illustrating a potentially multifaceted mechanism by which vitamin $D$ deficiency negatively affects persons with COPD. Deficiency of 25-OH-vitamin D has been hypothesized to promote chronic bronchitis. A study in the COPD Genetic Epidemiology cohort described similar improvement in symptom scores with increasing 25-OH-vitamin $\mathrm{D}$ levels and also a higher prevalence of radiographic findings associated with chronic bronchitis. ${ }^{51}$ However, a previous study conducted by our group ${ }^{22}$ did not find radiographic differences between those with 25-OH-Vitamin D levels $\geq 20$ and $<20$. Further study incorporating vitamin $D$ supplementation, measurement of muscular mass and function, markers of inflammation, and longitudinal outcomes could further define vitamin $\mathrm{D}$ deficiency as an important and modifiable comorbidity in COPD or if lower levels are simply a marker of poorer health status.

Associations between 25-OH-vitamin D and symptoms in the middle-aged group are seen when 25-OH-vitamin D is modeled continuously, but not by thresholds of sufficiency. The serum level at which 25-OH-vitamin $\mathrm{D}$ is associated with better outcomes may vary across diseases, ${ }^{52}$ and patients with very low 25-OH-vitamin D levels $(<10 \mathrm{ng} / \mathrm{ml})$ potentially represent the group who have worse outcomes. ${ }^{6}$ Further, the response to supplementation on vitamin $D$ levels may play a role in physical and symptom response, although the literature contains conflicting results. ${ }^{20,38,53-55}$ Participant-reported vitamin D supplementation did not impact the observed associations between 25-OH-vitamin $\mathrm{D}$ levels and symptom scores. Additionally, supplementation was not independently associated with better symptom scores in our study, however, the ascertainment of vitamin D supplementation, including dose, frequency, and compliance with therapy, was poor in SPIROMICS. These findings add to the importance of describing the 25-OH-vitamin $\mathrm{D}$ level at which supplementation will provide the most benefit and determining the importance of magnitude of response to supplementation versus merely achieving vitamin D sufficiency.

Better SGRQ total and subdomain scores in the middle-aged group are associated with higher vitamin $\mathrm{D}$ levels in this study. A large analysis of drug trial participants has associated poorer total SGRQ with worse COPD outcomes, including exacerbations. ${ }^{56}$ High physical and psychological comorbidity 
burden affects SGRQ scores in COPD patients. Literature suggests the SGRQ mainly assesses subjective symptoms and impairment and may not be an accurate indicator of physical functioning, ${ }^{57}$ explaining the lack of associations seen between vitamin D levels and 6MWT or VSAQ. Further, in the middle-aged group, there was not an association in Black participants when analyses were further subdivided by race. This may be due to differential vitamin $\mathrm{D}$ metabolism ${ }^{34}$ and represents an area in need of further investigation. Stronger associations seen between vitamin D levels and SGRQ scores as opposed to those observed with the CAT score, as seen in the analysis of the total cohort, have been noted elsewhere ${ }^{58}$ and may be due to the SGRQ's more granular nature.

This study has limitations. The associations presented are cross-sectional and do not prove causality between low vitamin $\mathrm{D}$ and increased symptoms. While the middle-aged cohort reported more time outdoors, this does not necessarily prove better overall health in this group. We do not have available data for recent pulmonary rehabilitation attendance among participants. Evaluating measures of sarcopenia would further enrich the analysis and better define phenotypes for future studies. Some important covariables including medication usage, time spent outdoors, and comorbidities were collected by patient report, introducing the potential for recall bias. Also, doses of vitamin D supplementation and whether the participants were compliant with this therapy, was not validated by the study. While modeling our continuous exposure as per $5 \mathrm{ng} / \mathrm{ml}$ 25-OH-vitamin D increase, we did not find differences in CAT and SGRQ Total scores that met MCID, however, these thresholds are reached at a $20 \mathrm{ng} / \mathrm{ml}$ change in 25-OH-vitamin D. The low number of participants with $25-\mathrm{OH}$-vitamin $\mathrm{D}<10 \mathrm{ng} / \mathrm{ml}$ limits our ability to accurately assess for threshold effects at that level which would otherwise be informative. We elected to not adjust for multiple comparisons given the controversy of using correction techniques when assessing significance using a universal mull not fitting the conceptual framework. ${ }^{59}$ Importantly, given the uniform nature of data collection in SPIROMICS, we would not expect these biases to differentially impact younger or older age groups.

In conclusion, increasing levels of vitamin $\mathrm{D}$, are associated with improved respiratory-specific symptoms, most notable in middle-aged participants. These relationships persisted when accounting for important confounders. These findings highlight the need to explore mechanisms more robustly by which vitamin D may improve symptoms. Additionally, study of the role of vitamin $D$ supplementation in the symptom burden of younger COPD patients is needed.

\section{Acknowledgements}

Author contributions: RMB and MBD conceptualized the study and produced the original manuscript. RMB performed data analysis. LRL reviewed the statistical approach and manuscript critically and revised the manuscript. All other coauthors collected study data, critically assessed methodological and statistical approach, critically reviewed manuscript, and revised the manuscript.

Data sharing: More information about the study and how to access SPIROMICS data is at www.spiromics. org.

The authors thank the SPIROMICS participants and participating physicians, investigators, and staff for making this research possible. We would like to acknowledge the following current and former investigators of the SPIROMICS sites and reading centers: Neil E. Alexis, MD; Wayne H. Anderson, PhD; Mehrdad Arjomandi, MD; Igor Barjaktarevic, MD, PhD; R. Graham Barr, MD, DrPH; Lori A. Bateman, MSc; Surya P. Bhatt, MD; Eugene R. Bleecker, MD; Richard C. Boucher, MD; Russell P. Bowler, MD, PhD; Stephanie A. Christenson, MD; Alejandro P. Comellas, MD; Christopher B. Cooper, MD, PhD; David J. Couper, PhD; Gerard J. Criner, MD; Ronald G. Crystal, MD; Jeffrey L. Curtis, MD; Claire M. Doerschuk, MD; Mark T. Dransfield, MD; Brad Drummond, MD; Christine M. Freeman, PhD; Craig Galban, PhD; MeiLan K. Han, MD, MS; Nadia N. Hansel, MD, MPH; Annette T. Hastie, PhD; Eric A. Hoffman, PhD; Yvonne Huang, MD; Robert J Kaner, MD; Richard E. Kanner, MD; Eric C. Kleerup, MD; Jerry A. Krishnan, MD, PhD; Lisa M. LaVange, PhD; Stephen C. Lazarus, MD; Fernando J. Martinez, MD, MS; Deborah A. Meyers, PhD; Wendy C. Moore, MD; John D. Newell, Jr, MD; Robert Paine, III, MD; Laura Paulin, MD, MHS; Stephen P. Peters, MD, PhD; Cheryl Pirozzi, MD; Nirupama Putcha, MD, MHS; Elizabeth C Oelsner, MD, MPH; Wanda K. O'Neal, PhD; Victor E. Ortega, MD, PhD; Sanjeev 
Raman, MBBS, MD; Stephen I. Rennard, MD; Donald P. Tashkin, MD; J. Michael Wells, MD; Robert A. Wise, MD; and Prescott G. Woodruff, MD, MPH. The project officers from the Lung Division of the National Heart, Lung, and Blood Institute were Lisa Postow, PhD, and Lisa Viviano, BSN; SPIROMICS was supported by contracts from the NIH/NHLBI (HHSN268200900013C, HHSN268200900014C, HHSN268200900015C, HHSN268200900016C, HHSN268200900017C, HHSN268200900018C, HHSN268200900019C, HHSN268200900020C), and a grant from the NIH/NHLBI (U01 HL137880), grants from the NIH/NHLBI (U01 HL137880 and U24 HL141762), and supplemented by contributions made through the Foundation for the $\mathrm{NIH}$ and the COPD Foundation from AstraZeneca/ MedImmune; Bayer; Bellerophon Therapeutics; Boehringer- Ingelheim Pharmaceuticals, Inc.; Chiesi Farmaceutici S.p.A.; Forest Research Institute, Inc.; GlaxoSmithKline; Grifols Therapeutics, Inc.; Ikaria, Inc.; Novartis Pharmaceuticals Corporation; Nycomed $\mathrm{GmbH}$; ProterixBio; Regeneron Pharmaceuticals, Inc.; Sanofi; Sunovion; Takeda Pharmaceutical Company; and Theravance Biopharma and Mylan.

\section{Declaration of Interest}

RMB Received Grants from the National Institutes of Health (NIH) during the conduct of this study. DJC received grants from the NIH and the COPD Foundation during the conduct of this study. IZB reports grants from the National Heart, Lung, and Blood Institute (NHLBI) during the conduct of the study; grants and personal fees from Theravance and Mylan, grants from Amgen, personal fees from Astra Zeneca, GlaxoSmithKline, Boehringer Ingelheim, Verona Pharma, and Grifols outside the submitted work. CBC reports grants from the NIH/NHLBI, grants from the Foundation of the NIH, and grants from the COPD Foundation during the conduct of the study; personal fees from PulmonX, NUVAIRA and MGC Diagnostics and other from GlaxoSmithKline, outside the submitted work. MKH reports personal fees from GlaxoSmithKline, AstraZeneca, Boehringer Ingelheim, Mylan, Merck, and Verona, and other from Novartis and Sunovion, outside the submitted work. PGW reports personal fees from Regeneron, Sanof, Theravance, NGM, Glenmark, Genentech, and Amgen, outside the submitted work. SCL reports grants from the NIH. RP III reports grants from the NHLBI and grants from COPD Foundation, during the conduct of the study; grants from the Department of Veterans Affairs, and personal fees from Partner Therapeutics, outside the submitted work. APC reports grants from the NIH, during the conduct of the study; grants from the NIH, non-financial support from VIDA, and personal fees from GlaxoSmithKline, outside the submitted work. NP reports grants from the NIH. RAW reports grants and personal fees from AstraZeneca / Medimmune / Pearl, grants and personal fees from Boehringer Ingelheim, grants and personal fees from GlaxoSmithKline, personal fees from Contrafect, Roche, Merck, Circassia, Pneuma, Verona, Mylan/Theravance, AbbVie, ChemRx, Propeller Health, Kiniksa, Bristol Myers Squibb, Galderma, and Kinevant and grants from Sanofi-Aventis, outside the submitted work. MBD reports grants from the NIH and the NHLBI during the conduct of the study; personal fees from BoehringerIngelheim, GlaxoSmithKline, AstraZeneca, MylanTheravance, Parion, Midmark, and Phillips and grants from the Department of Defense outside the submitted work. WWL, TMP, RPB, LRL and TTB have nothing to disclose. 


\section{References}

1. Lopez AD, Shibuya K, Rao C, et al. Chronic obstructive pulmonary disease: current burden and future projections. Eur Respir J. 2006;27(2):397-412.

doi: https://doi.org/10.1183/09031936.06.00025805

2. Miravitlles M, Ribera A. Understanding the impact of symptoms on the burden of COPD. Respir Res. 2017;18(1):67.

doi: https://doi.org/10.1186/s12931-017-0548-3

3. Burkes RM, Donohue JF. An update on the global initiative for chronic obstructive lung disease 2017 guidelines with a focus on classification and management of stable COPD. Respir Care. 2018;63(6):749-758. doi: https://doi.org/10.4187/respcare.06174

4. Calverley PM, Anderson JA, Celli B, et al. Salmeterol and fluticasone propionate and survival in chronic obstructive pulmonary disease. $N$ Engl J Med. 2007;356(8):775-789.

doi: https://doi.org/10.1056/NEJMoa063070

5. Wedzicha JA, Banerji D, Chapman $\mathrm{KR}$, et al. Indacaterolglycopyrronium versus salmeterol-fluticasone for COPD. $N$ Engl $J$ Med. 2016;374(23):2222-2234.

doi: https://doi.org/10.1056/NEJMoa1516385

6. Lehouck A, Mathieu C, Carremans C, et al. High doses of vitamin D to reduce exacerbations in chronic obstructive pulmonary disease: a randomized trial. Ann Intern Med. 2012;156(2):105-114. doi: https://doi.org/10.7326/0003-4819-156-2-201201170-00004

7. Tashkin DP, Celli B, Senn S, et al. A 4-year trial of tiotropium in chronic obstructive pulmonary disease. N Engl J Med. 2008;359(15):15431554. doi: https://doi.org/10.1056/NEJMoa0805800

8. Tinkelman D, Nordyke RJ, Isonaka S, George D, DesFosses K, Nonikov D. The impact of chronic obstructive pulmonary disease on long-term disability costs. J Manag Care Pharm. 2005;11(1):25-32. doi: https://doi.org/10.18553/jmcp.2005.11.1.25

9. Martinez CH, Diaz AA, Parulekar AD, et al. Age-related differences in health-related quality of life in COPD: an analysis of the COPDGene and SPIROMICS cohorts. Chest. 2016;149(4):927-935. doi: https://doi.org/10.1016/j.chest.2015.11.025

10. Berry CE, Han MK, Thompson B, et al. Older adults with chronic lung disease report less limitation compared with younger adults with similar lung function impairment. Ann Am Thorac Soc. 2015;12(1):2126. doi: https://doi.org/10.1513/AnnalsATS.201407-312OC

11. Tack M, Altose MD, Cherniack NS. Effect of aging on the perception of resistive ventilatory loads. Am Rev Respir Dis. 1982;126(3):463-467. doi: https://doi.org/10.1164/arrd.1982.126.3.463

12. Holm KE, Plaufcan MR, Ford DW, et al. The impact of age on outcomes in chronic obstructive pulmonary disease differs by relationship status. J Behav Med. 2014;37(4):654-663. doi: https://doi.org/10.1007/s10865-013-9516-7
13. Simmering JE, Polgreen LA, Comellas AP, Cavanaugh JE, Polgreen PM. Identifying patients with COPD at high risk of readmission. Chronic Obstr Pulm Dis. 2016;3(4):729-738. doi: https://doi.org/10.15326/jcopdf.3.4.2016.0136

14. Putcha N, Puhan MA, Drummond MB, et al. A simplified score to quantify comorbidity in COPD. PLoS One. 2014;9(12):e114438. doi: https://doi.org/10.1371/journal.pone.0114438

15. Hiller AL, Murchison CF, Lobb BM, O'Connor S, O'Connor M, Quinn JF. A randomized, controlled pilot study of the effects of vitamin D supplementation on balance in Parkinson's disease: Does age matter? PloS One. 2018;13(9):e0203637.

doi: https://doi.org/10.1371/journal.pone.0203637

16. Manoy P, Yuktanandana P, Tanavalee A, et al. Vitamin D supplementation improves quality of life and physical performance in osteoarthritis patients. Nutrients. 2017;9(8). doi: https://doi.org/10.3390/nu9080799

17. Burkes RM, Drummond MB. Initiating drug therapy in early stage chronic obstructive pulmonary disease: does it impact the course and outcome? Curr Opin Pulm Med.2019;25(2):132-137. doi: https://doi.org/10.1097/MCP.0000000000000553

18. Janssens W, Bouillon R, Claes B, et al. Vitamin D deficiency is highly prevalent in COPD and correlates with variants in the vitamin D-binding gene. Thorax. 2010;65(3):215-220. doi: https://doi.org/10.1136/thx.2009.120659

19. Black PN, Scragg R. Relationship between serum 25-hydroxyvitamin $\mathrm{D}$ and pulmonary function in the third national health and nutrition examination survey. Chest. 2005;128(6):3792-3798. doi: https://doi.org/10.1378/chest.128.6.3792

20. Carson EL, Pourshahidi LK, Madigan SM, et al. Vitamin D status is associated with muscle strength and quality of life in patients with COPD: a seasonal prospective observation study. Int J Chron Obstruct Pulmon Dis. 2018;13:2613-2622. doi: https://doi.org/10.2147/COPD.S166919

21. Jolliffe DA, Greenberg L, Hooper RL, et al. Vitamin D to prevent exacerbations of COPD: systematic review and meta-analysis of individual participant data from randomised controlled trials. Thorax. 2019;74:337-345.

doi: https://doi.org/10.1136/thoraxjnl-2018-212092

22. Burkes RM, Ceppe AS, Doerschuk CM, et al. Associations among 25-hydroxyvitamin D levels, lung function, and exacerbation outcomes in COPD: an analysis of the SPIROMICS cohort. Chest. 2020;157(4):856-865.

doi: https://doi.org/10.1016/j.chest.2019.11.047

23. Beauchet O, Annweiler C, Verghese J, Fantino B, Herrmann FR, Allali G. Biology of gait control: vitamin D involvement. Neurology. 2011;76(19):1617-1622.

doi: https://doi.org/10.1212/WNL.0b013e318219fb08 
24. Ringbaek T, Martinez G, Durakovic A, et al. Vitamin D status in patients with chronic obstructive pulmonary disease who participate in pulmonary rehabilitation. J Cardiopulm Rehabil Prev. 2011;31(4):261267. doi: https://doi.org/10.1097/HCR.0b013e31821c13aa

25. Maltais F, Decramer M, Casaburi R, et al. An official American Thoracic Society/European Respiratory Society statement: update on limb muscle dysfunction in chronic obstructive pulmonary disease. Am J Respir Crit Care Med. 2014;189(9):e15-e62. doi: https://doi.org/10.1164/rccm.201402-0373ST

26. Couper D, LaVange LM, Han M, et al. Design of the subpopulations and intermediate outcomes in COPD Study (SPIROMICS). Thorax. 2014;69(5):491-494.

doi: https://doi.org/10.1136/thoraxjnl-2013-203897

27. Miller MR, Hankinson J, Brusasco V, et al. Standardisation of spirometry. Eur Repir J. 2005;26(2):319-338. doi: https://doi.org/10.1183/09031936.05.00034805

28. Bestall JC, Paul EA, Garrod R, Garnham R, Jones PW, Wedzicha JA. Usefulness of the Medical Research Council (MRC) dyspnoea scale as a measure of disability in patients with chronic obstructive pulmonary disease. Thorax. 1999;54(7):581-586. doi: https://doi.org/10.1136/thx.54.7.581

29. Jones PW, Harding G, Berry P, Wiklund I, Chen WH, Kline Leidy N. Development and first validation of the COPD assessment test. Eur Respir J. 2009;34(3):648-654.

doi: https://doi.org/10.1183/09031936.00102509

30. Jones PW, Quirk FH, Baveystock CM, Littlejohns P. A self-complete measure of health status for chronic airflow limitation. The St. George's respiratory questionnaire. Am Rev Respir Dis. 1992;145(6):1321-1327. doi: https://doi.org/10.1164/ajrccm/145.6.1321

31. Lo C, Liang W-M, Hang L-W, Wu T-C, Chang Y-J, Chang C-H. A psychometric assessment of the St. George's respiratory questionnaire in patients with COPD using Rasch model analysis. Health Qual Life Outcomes. 2015;13:131.

doi: https://doi.org/10.1186/s12955-015-0320-7

32. Myers J, Bader D, Madhavan R, Froelicher V. Validation of a specific activity questionnaire to estimate exercise tolerance in patients referred for exercise testing. Am Heart J. 2001;142(6):1041-1046. doi: https://doi.org/10.1067/mhj.2001.118740

33. Lederer DJ, Bell SC, Branson RD, et al. Control of confounding and reporting of results in causal inference studies. Guidance for authors from editors of respiratory, sleep, and critical care journals. Ann Am Thorac Soc. 2019;16(1):22-28.

doi: https://doi.org/10.1513/AnnalsATS.201808-564PS

34. Hsu S, Hoofnagle AN, Gupta DK, et al. Race, ancestry, and vitamin D metabolism: the multi-ethnic study of atherosclerosis. $J$ Clin Endocrinol Diabetes. 2020;105(12):e4337-4350. doi: https://doi. org/10.1210/clinem/dgaa612
35. Gawecki F, Myers J, Shovlin CL. Veterans Specific Activity Questionnaire (VSAQ): a new and efficient method of assessing exercise capacity in patients with pulmonary arteriovenous malformations. BMJ Open Respir Res. 2019;6(1):e000351. doi: https://doi.org/10.1136/bmjresp-2018-000351

36. Global Initiative for Chronic Obstructive Lung Disease (GOLD). Global strategy for the diagnosis, management, and prevention of chronic obstructive pulmonary disease, 2020 report. GOLD website. Published December 2019. Accessed December 2020. https://goldcopd.org/gold-reports/

37. Wintermeyer $\mathrm{E}$, Ihle $\mathrm{C}$, Ehnert $\mathrm{S}$, et al. Crucial role of vitamin $\mathrm{D}$ in the musculoskeletal system. Nutrients. 2016;8(6):319. doi: https://doi.org/10.3390/nu8060319

38. Hornikx M, Van Remoortel H, Lehouck A, et al. Vitamin D supplementation during rehabilitation in COPD: a secondary analysis of a randomized trial. Respir Res. 2012;13(1):84. doi: https://doi.org/10.1186/1465-9921-13-84

39. van Beers M, Rutten-van Molken M, van de Bool C, et al. Clinical outcome and cost-effectiveness of a 1-year nutritional intervention programme in COPD patients with low muscle mass: the randomized controlled NUTRAIN trial. Clin Nutr. 2019;39(2):405-413. doi: https://doi.org/10.1016/j.clnu.2019.03.001

40. Fried TR, Vaz Fragoso CA, Rabow MW. Caring for the older person with chronic obstructive pulmonary disease. JAMA. 2012;308(12):12541263. doi: https://doi.org/10.1001/jama.2012.12422

41. Gooneratne NS, Patel NP, Corcoran A. Chronic obstructive pulmonary disease diagnosis and management in older adults. J Am Geriatr Soc. 2010;58(6):1153-1162.

doi: https://doi.org/10.1111/j.1532-5415.2010.02875.x

42. Putcha N, Drummond MB, Wise RA, Hansel NN. Comorbidities and chronic obstructive pulmonary disease: prevalence, influence on outcomes, and management. Semin Respir Crit Care Med. 2015;36(4):575-591. doi: https://doi.org/10.1055/s-0035-1556063

43. Putcha N, Fawzy A, Paul GG, et al. Anemia and adverse outcomes in a chronic obstructive pulmonary disease population with a high burden of comorbidities. An analysis from SPIROMICS. Ann Am Thorac Soc. 2018;15(6):710-717.

doi: https://doi.org/10.1513/AnnalsATS.201708-687OC

44. Labaki WW, Xia M, Murray S, et al. NT-proBNP in stable COPD and future exacerbation risk: analysis of the SPIROMICS cohort. Respir Med. 2018;140:87-93.

doi: https://doi.org/10.1016/j.rmed.2018.06.005

45. Zeidler MR, Martin JL, Kleerup EC, et al. Sleep disruption as a predictor of quality of life among patients in the subpopulations and intermediate outcome measures in COPD study (SPIROMICS). Sleep. 2018;41(5). doi: https://doi.org/10.1093/sleep/zsy044 
46. Papaioannou O, Karampitsakos T, Barbayianni I, et al. Metabolic disorders in chronic lung diseases. Front Med (Lausanne). 2018;4:246. doi: https://doi.org/10.3389/fmed.2017.00246

47. Gombart AF, Bhan I, Borregaard N, et al. Low plasma level of cathelicidin antimicrobial peptide (hCAP18) predicts increased infectious disease mortality in patients undergoing hemodialysis. Clin Infect Dis. 2009;48(4):418-424. doi: https://doi.org/10.1086/596314

48. Zhang Y, Leung DY, Richers BN, et al. Vitamin D inhibits monocyte/ macrophage proinflammatory cytokine production by targeting MAPK phosphatase-1. JImmunol. 2012;188(5):2127-2135. doi: https://doi.org/10.4049/jimmunol.1102412

49. Cantorna MT, Yu S, Bruce D. The paradoxical effects of vitamin D on type-1 mediated immunity. Mol Aspects Med. 2008;29(6):369-375. doi: https://doi.org/10.1016/j.mam.2008.04.004

50. Kim C, Jung JY, Kim YS, et al. Vitamin D deficiency is associated with rapid decline in exercise capacity in male patients with chronic obstructive pulmonary disease. Respiration. 2016;91(5):351-358. doi: https://doi.org/10.1159/000445266

51. Ghosh AJ, Moll M, Hayden LP, Bon J, Regan E, Hersh CP. Vitamin $D$ deficiency is associated with respiratory symptoms and airway wall thickening in smokers with and without COPD: a prospective cohort study. BMC Pulm Med. 2020;20(1):123.

doi: https://doi.org/10.1186/s12890-020-1148-4

52. Wu F, Wills K, Laslett LL, et al. Cut-points for associations between vitamin D status and multiple musculoskeletal outcomes in middleaged women. Osteoporos Int. 2017;28(2):505-515. doi: https://doi.org/10.1007/s00198-016-3754-9

53. Szymczak I, Pawliczak R. Can vitamin D help in achieving asthma control? Vitamin D "revisited": an updated insight. Adv Respir Med. 2018;86(2):103-109. doi: https://doi.org/10.5603/ARM.2018.0015

54. Rafiq R, Prins HJ, Boersma WG, et al. Effects of daily vitamin D supplementation on respiratory muscle strength and physical performance in vitamin D-deficient COPD patients: a pilot trial. Int $J$ Chron Obstruct Pulmon Dis. 2017;12:2583-2592. doi: https://doi.org/10.2147/COPD.S132117

55. MoosaviSAJ, ShoushtariMH. The effects of vitamin D supplementation on pulmonary function of chronic obstructive pulmonary disease patients, before and after clinical trial. Diseases. 2015;3(4):253-259. doi: https://doi.org/10.3390/diseases3040253

56. Mullerova H, Gelhorn H, Wilson H, et al. St George's Respiratory Questionnaire score predicts outcomes in patients with COPD: analysis of individual patient data in the COPD biomarkers qualification consortium database. Chronic Obstr Pulm Dis. 2017;4(2):141-149. doi: https://doi.org/ 10.15326/jcopdf.4.2.2017.0131

57. Daudey L, Peters JB, Molema J, et al. Health status in COPD cannot be measured by the St George's Respiratory Questionnaire alone: an evaluation of the underlying concepts of this questionnaire. Respir Res. 2010;11:98 doi: https://doi.org/10.1186/1465-9921-11-98
58. Morishita-Katsu M, Nishimura K, Taniguchi H, et al. The COPD assessment test and St George's Respiratory Questionnaire: are they equivalent in subjects with COPD? Int $J$ Chron Obstruct Pulmon Dis. 2016;11:1543-1551.

doi: https://doi.org/10.2147/COPD.S104947

59. Perneger TV. What's wrong with Bonferroni adjustments. BMJ. 1998;316(7139):1236-1238.

doi: https://doi.org/10.1136/bmj.316.7139.1236 